342

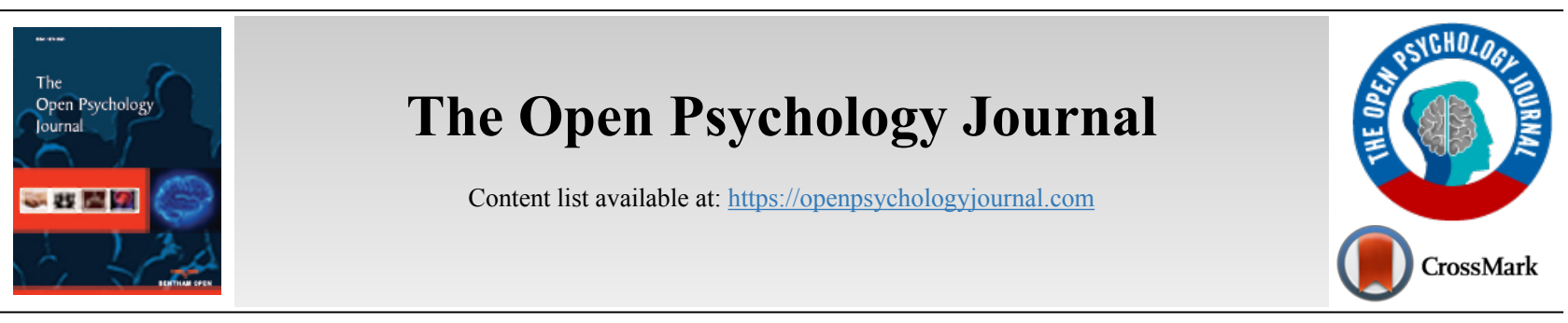

RESEARCH ARTICLE

\title{
Prosocial Behaviors Among the Vietnamese Population During the COVID-19 Pandemic: Implications for Social Education Programs
}

Trang Vu Thu, ${ }^{1, *}$, Dung $\mathrm{Vu}^{2}$, Kyesun Lee ${ }^{3}$, Lan Nguyen Thi Mai ${ }^{2}$, Nguyet Le Minh ${ }^{1}$, Phan Phung Dinh Bao ${ }^{4}$ Ngoc Tran Hoang Thi Diem ${ }^{3}$, Long Nguyen Xuan ${ }^{5}$ and Nam Pham Tien ${ }^{6}$

\author{
${ }^{1}$ National University of Education, Hanoi City, Vietnam \\ ${ }^{2}$ Institute of Psychology, Hanoi City, Vietnam \\ ${ }^{3}$ Department of Korean Language, Thanglong University, Hanoi City, Vietnam \\ ${ }^{4}$ University of Education, Hue University, Hue City, Vietnam \\ ${ }^{5}$ University of Languages and International Studies, Vietnam National University, Hanoi City, Vietnam \\ ${ }^{6}$ Hanoi University of Public Health, Faculty of Social Work, Hanoi City, Vietnam
}

\begin{abstract}
:
Objective:

The objectives of this study were to estimate the prevalence of prosocial behaviors and to examine associated factors among the Vietnamese people during the COVID-19 pandemic.

Methods:

Two hundred and ninety-two Vietnamese people participated in the study through web-based respondent network sampling.

Result:

Findings showed that the prevalence of high prosocial behaviors was $75.3 \%$.

Conclusion:

In the multivariable regression models, significant factors for prosocial behaviors were institutional trust and age. Implications for social education programs were also discussed in this study.
\end{abstract}

Keywords: Prosocial behavior, Institutional trust, COVID-19 pandemic, Vietnamese population, Social education program, Social community.

\begin{tabular}{|l|l|l|l|}
\hline Article History & Received: June 28, 2021 & Revised: November 9, 2021 & Accepted: November 29, 2021
\end{tabular}

\section{INTRODUCTION}

Prosocial behaviors are behaviors that benefit others [1]. As its name suggests, prosocial behaviors are the core of building a social community. In crises, whether natural catastrophes or civil disasters, prosocial behaviors become even more important to provide immediate assistance to those in need, especially when the state response is slow or inadequate [2].

It should be noted that in crises, not only are people expected to help their close ones like family members or neighbors, but they are also encouraged to help strangers because of the large-scale impacts of crises. The COVID-19 pandemic provides various examples of the necessity of indi-

* Address correspondence to this author at the Graduate Academy of Social Sciences, Vietnam Academy of Social Sciences, Hanoi City, Vietnam;

Tel: 0964525858; E-mail: trangvuthu90@gmail.com viduals' and entities' prosocial behaviors towards strangers. In India, as the second wave of COVID-19 hits the country, citizens and hospitals turn to social media in search of medical support such as oxygen and beds [3]. In Vietnam, the media has recorded cases of donation even among the poor for COVID-19 patients, quarantined people, and healthcare staff [4], or initiatives such as rice ATM [5] and zero-dong supermarkets [6]. In crises, individual support through prosocial acts is key to community resilience and quick recovery.

The other-oriented nature of prosocial acts poses a challenge to members of collectivistic cultures. In both individualistic and collectivistic cultures, people are more likely to help people close to them or people they can trust and less likely to help strangers [7]. In collectivistic cultures, this trend is even stronger because collectivistic cultures, such as 
Vietnamese culture, emphasize the in-group; the benefits of strangers (out-group) are not significant $[8-10]$. In line with this argument, in a review of data from 21 countries, Knafo, Schwartz [11] found a strong negative correlation between high cultural embeddedness (i.e., the tendency to focus on in-group welfare) and helping behavior towards strangers. León and Finkelstein [12] found that collectivists are inclined to support colleagues and the organization through organizational citizenship behavior. Puyod and Charoensukmongkol [13] reported that employees who care about organizational development were more willing to change to respond to the COVID-19 crisis.

Irwin [14] proposed that institutional trust - trust in the government, laws, and monitoring systems - promotes prosocial acts in collectivistic cultures. High institutional trust assures people that selfish people are punished for threatening social order, thereby reducing the risks individuals face when helping out-groups. Supporting this argument, while the Japanese had lower trust in strangers than Americans [15], the Japanese cooperated more with a sanctioning system than with none [16]. In other words, while collectivists have low general trust, the sanctioning system increases their institutional trust and also increases their prosocial behaviors. Andriani and Sabatini [17] found that among Palestinians, as members of a collectivistic culture, institutional trust was positively correlated with one's perception of other-oriented behaviors. When Palestinians trusted the government and judicial system, they were less likely to accept nonparticipation in the election, violate traffic rules, or purchase stolen goods.

Few studies actually tested the effect of institutional trust on prosocial behaviors in collectivistic cultures. For example, Andriani and Sabatini [17] aimed to measure the impact of institutional trust on prosocial behaviors of Palestinians, but what they actually measured was a commitment to social norms, not altruistic behaviors.

The COVID-19 pandemic presents ideal opportunities to examine the relationship between institutional trust and prosocial behaviors in collectivistic cultures. Extreme situations like the COVID-19 pandemic or natural disasters require prosocial behaviors towards out-groups. At the same time, institutional trust also becomes a central issue during crises. Political institutions such as the government, politicians, police, and the legal system hold responsibility for crisis management. When they fail to mitigate and terminate a crisis, the institutional trust decreases $[18,19]$. Low institutional trust leads to anxiety and uncertainty of the ability to overcome the difficult times [20], while high institutional trust facilitates cooperation and economic success during economic crises, as well as compliance with health policies during health crises $[21,22]$.

The link between institutional trust, crises, and prosocial behaviors underlines this study. The aim of the present study is twofold: (a) to estimate the prevalence of prosocial behaviors among the Vietnamese people during the COVID-19 pandemic, and (b) to examine predictors of prosocial behaviors during the COVID-19 pandemic, focusing on the impact of institutional trust. We hypothesized that the more people trusted the government's response to the COVID-19 pandemic, the more they conducted prosocial behaviors.

\subsection{Theories Explaining Prosocial Behaviors in Collectivistic Cultures}

At least 5 theories have been proposed to explain the occurrence of prosocial behaviors. We can look at the five theories explaining prosocial behaviors in two ways: theories that focus on personal benefits of prosocial behaviors (including kin selection theory, reciprocal altruism theory, cost-reward theory, and negative state relief theory) and theories that focus on others (such as empathy-altruism theory and cost-reward theory). Cost-reward theory falls into both categories because the cost-reward analysis can be directed at the helper and the helped.

Kin selection theory stresses the evolutionary advantage of prosocial behaviors towards cohort members [23]. We are genetically programmed to support our kins because their survival helps us to pass on our genes. Burnstein, Crandall, and Kitayama (1994) [7] found that when having to choose between helping a sister, a cousin, and an acquaintance, people tend to help those closest to them first. This theory was later extended into reciprocal altruism theory, which states that we help in the expectation of something in return, thereby increasing our chances of survival. This new version of the kin selection theory allows researchers to explain helping behaviors towards non-relatives.

Empathy-altruism theory seeks to explain prosocial behaviors in a more emotional manner [24]. We help others when we feel empathetic with their sufferings. In contrast to empathy-altruism theory, negative state relief theory claims that observing people's sufferings causes us distress, and we help to reduce the negative state we are in [25].

Cost-reward theory explains prosocial behaviors as the result of a cost and reward analysis. People weigh the pros and cons of helping a person and only choose to help when the benefits of helping outweigh the costs [26]. A person might help because what he receives (money, praises, positive feelings, etc.) is more than what he pays (time, danger, etc.). Note that the costs and rewards do not limit the helpers themselves but also the beneficiaries. For example, when a person sees an emergency but does not know how to help, he might refrain from helping because the concerns are greater than the rewards [27].

Cost-reward theory can account for prosocial behavior in collectivist culture through the cost-reward analysis of trust. Prosocial behavior is driven by trust. People are willing to help others at the cost of personal benefits when they perceive a low cost of trusting others [28]. In collectivistic cultures, general trust, or trust in others, is not enough to motivate prosocial behaviors. Institutional trust assures collectivists that selfish people would be punished, thus reducing the cost of helping a stranger.

Two mechanisms can explain the effect of institutional trust on prosocial behaviors in collectivistic cultures. The first mechanism proposed by Kumlin and Rothstein [29] stresses the role of institutional trust in creating social responsibility. When we trust that our state cares for the welfare of its citizens, we 
understand that the state puts equal treatment and fairness at the priority; thus, we will also adopt these principles to support the welfare of others. For example, most Scandinavian states distribute welfare universally, so a higher rate of institutional trust and prosocial behaviors was observed in these states [29]. On the contrary, when states distribute welfare in a nonuniversal manner, institutional trust becomes questionable, and social capital is undermined. Citizens who feel that it is the state, not themselves, should then hold responsible for ensuring the benefits of its citizens. Supporting this argument, Evers and Gesthuizen [30] found that institutional trust in individualistic cultures such as West European countries and the United States was negatively linked to donation behaviors.

The second mechanism proposed by Irwin [14] highlights the role of institutional trust in ensuring a good monitoring system towards cheating behaviors. A trustable government protects the benefits of the helpers by punishing cheating or law-breaking behaviors, thus indirectly encouraging prosocial behaviors in the helpers. For example, during the COVID-19 pandemic, when wearing a mask is a must, the act of stockpiling masks is deemed socially undesirable, while the act of giving masks to people in need or who cannot afford them is socially desirable. An effective government will punish panic buying and stockpiling while also encouraging mask distribution. If citizens have high trust in the government, they will reduce stockpiling for fear of punishment and increase giving the masks to conform to societal standards, even when their acts are anonymous.

In practice, both mechanisms provide useful tools for the government to facilitate prosocial behaviors in collectivistic cultures through institutional trust. This study was conducted to test the link between institutional trust and prosocial behaviors in a collectivistic setting in order to facilitate prosocial behaviors in crises.

\section{METHODS}

\subsection{Study Design}

This was a cross-sectional study. Due to gathering restrictions during COVID-19, the study was conducted online. The questionnaire was designed on Google Forms and distributed through the two most popular social media platforms in Vietnam: Facebook and Zalo (similar to "Skype"). Data were collected from September 2nd to September 18th, 2020 .

\subsection{Participants}

Participants in this study were Vietnamese, aged 16 and above. Participants must live in Vietnam during the pandemic period and have Internet access to answer the online survey.

A sample was obtained through the snowballing method. An online self-administered questionnaire was created and spread among the online social networks of the authors. Respondents received the questionnaire along with a cover letter explaining the purpose of the study. They were informed that the survey distribution was voluntary, and respondents did not receive anything in return for answering or spreading the questionnaire. The final sample size included 292 participants.

\subsection{Study Variables}

Our main dependent variable was prosocial behavior (low prosocial behavior; and high prosocial behavior).

Independent variables included age (below 30 years old, 30-40 years old, and above 40 years old), gender (female, and male), occupation (students, teachers/lecturers, government employees, employees in the private sector, businessmen, and freelances, and medical staff), educational achievement (high school, bachelor, and postgraduate), and institutional trust (low trust, and high trust).

\subsection{Measures}

Prosocial behavior: We used the COVID-19 Prosocial Experience scale by Alvis, Shook [31] to measure prosocial behaviors. The scale was developed to measure adolescents' engagement in prosocial behaviors during the COVID-19 pandemic. In this study, the help-receiving behaviors were omitted, leaving the scale with 8 items on engagement in prosocial behaviors. Examples of prosocial behaviors surveyed were giving money, buying food and necessities for people in quarantine, helping with childcare, etc. Participants rated how often they helped their family, friends, neighbors, and strangers during the pandemic on a 5-point scale (1-never to 5-always). The total score ranged from 0 to 40 ; a higher score implied higher prosocial behavior. The scale showed good reliability in this study (Cronbach alpha $=0.89$ ). We applied the cutoff point method to classify prosocial behavior: respondents with a score of 20 or higher were classified as high prosocial behaviors, while a score lower than 20 was classified as low prosocial behaviors.

Institutional trust: Institutional trust, i.e., trust in the government's response towards the COVID-19 pandemic, was measured by 8 items, including 3 items adapted from Han, Zheng [32] and 5 items adapted from Sibley, Greaves [33]. The total score ranged from 0 to 40 ; a higher score implied higher trust. The scale showed good reliability: Cronbach alpha = 0.788 . In this study, we defined high institutional trust as having a score of $\geq 20$ and low institutional trust as a score of $<$ 20 .

\subsection{Statistical Analysis}

To compare the differences in respondents' prosocial behavior, we used Chi-square by Stata 14.2 Survey package. Moreover, we examined the associated factors for prosocial behaviors by performing the Multivariate Poisson regression model with robust error variances [34 - 36]. Prevalence Ratios (PRs) were calculated, together with corresponding 95\% Confidence Interval (CI), and we used a significance level of $\mathrm{p}<0.05$.

\subsection{Ethical Considerations}

Ethical approval of this study was obtained from the Scientific and Ethical Committee, Vietnam Association of Psychology, under Decision no. 12/2020/HTLHVN-DD. Participants gave their informed consent by answering a yes-no question on voluntary participation before the main questionnaire. 


\section{RESULT}

\subsection{Sample Characteristics}

The participants' characteristics are shown in Table $\mathbf{1}$. Most participants were female $(61.0 \%)$, aged under 40 years old $(74.4 \%)$. More than $40 \%$ of the sample were teachers and lecturers, and $23.3 \%$ were students, leading to a high prevalence of respondents with a bachelor's degree or above (64.4\%).

A significantly high prevalence of respondents in this study (75.3\%) reported high prosocial behaviors. Nearly all respondents had high trust in the government's response to the
COVID-19 pandemic (93.2\%).

\subsection{Prosocial Behavior During the COVID-19 Pandemic}

People over 40 years old reported having high prosocial behaviors $(32.3 \%$ vs $5.6 \%, \mathrm{p}<0.001)$. A higher prevalence of prosocial behaviors was reported in teachers/lecturers and medical staff $(43.2 \%$ vs $30.6 \%, 2.3 \%$ vs $1.4 \%, \mathrm{p}=0.028$, respectively).

A higher prevalence of prosocial behavior was found in people having high institutional trust $(95.9 \%$ vs. $84.7 \%, \mathrm{p}=$ 0.001) (Table 2).

Table 1. Demographic statistics of respondents.

\begin{tabular}{|c|c|}
\hline Characteristics & n (\%) \\
\hline \multicolumn{2}{|l|}{ Age } \\
\hline Below 30 years old & $98(33.6)$ \\
\hline $30-40$ years old & $119(40.8)$ \\
\hline Above 40 years old & $75(25.7)$ \\
\hline \multicolumn{2}{|l|}{ Gender } \\
\hline Female & $178(61.0)$ \\
\hline Male & $114(39.0)$ \\
\hline \multicolumn{2}{|l|}{ Occupation } \\
\hline Students & $68(23.3)$ \\
\hline Teachers/Lecturers & $117(40.1)$ \\
\hline Government employees & $44(15.1)$ \\
\hline Employees in private organizations & $19(6.5)$ \\
\hline Businessmen, freelances & $38(13.0)$ \\
\hline Medical staff & $6(2.1)$ \\
\hline \multicolumn{2}{|l|}{ Educational achievement } \\
\hline Highschool & $104(35.6)$ \\
\hline Bachelor & $142(48.6)$ \\
\hline Postgraduate & $46(15.8)$ \\
\hline \multicolumn{2}{|l|}{ Institutional trust } \\
\hline Low trust & $20(6.8)$ \\
\hline High trust & $272(93.2)$ \\
\hline \multicolumn{2}{|l|}{ Prosocial behavior } \\
\hline Low prosocial behavior & $72(24.7)$ \\
\hline High prosocial behavior & $220(75.3)$ \\
\hline $\mathbf{N}=$ & 292 \\
\hline
\end{tabular}

Table 2. Prosocial behavior of respondents.

\begin{tabular}{|l|c|c|}
\hline Columns by: Prosocial Behavior & Low & High \\
\hline $\mathbf{n}(\mathbf{\%})$ & $72(24.4)$ & $220(75.3)$ \\
\hline Age, $\mathbf{n}(\%)$ & & \\
\hline Below 30 years old & $35(48.6)$ & $<\mathbf{0 0 1}$ \\
\hline $30-40$ years old & $33(45.8)$ & $63(28.6)$ \\
\hline Above 40 years old & $4(5.6)$ & $86(39.1)$ \\
\hline Gender, $\mathbf{n}(\%)$ & & $71(32.3)$ \\
\hline Female & $46(63.9)$ & \\
\hline Male & $26(36.1)$ & $132(60.0)$ \\
\hline Occupation, $\mathbf{n}(\%)$ & & $88(40.0)$ \\
\hline Students & & \\
\hline
\end{tabular}


(Table 2) contd.....

\begin{tabular}{|c|c|c|c|}
\hline Teachers/Lecturers & $22(30.6)$ & $95(43.2)$ & \\
\hline Admin & $17(23.6)$ & $46(20.9)$ & \\
\hline Businessmen, freelances & $6(8.3)$ & $32(14.5)$ & \\
\hline Medical staff & $1(1.4)$ & $5(2.3)$ & \\
\hline Educational achievement, $n(\%)$ & & & 0.26 \\
\hline Highschool & $30(41.7)$ & $74(33.6)$ & \\
\hline Bachelor & $29(40.3)$ & $113(51.4)$ & \\
\hline Postgraduate & $13(18.1)$ & $33(15.0)$ & \\
\hline Institutional trust, $\mathbf{n}(\%)$ & & & 0.001 \\
\hline Low trust & $11(15.3)$ & $9(4.1)$ & \\
\hline High trust & $61(84.7)$ & $211(95.9)$ & \\
\hline \multicolumn{4}{|l|}{ Statistical comparison using: } \\
\hline \multicolumn{4}{|l|}{ Chi-square test for categorical variable - display as $\mathrm{n}(\%)$} \\
\hline The bold $\mathrm{p}$-value indicated statistical significance $(\mathrm{p}<0.05)$. & & & \\
\hline
\end{tabular}

Table 3. Factors associated with prosocial behaviors.

\begin{tabular}{|c|c|c|c|}
\hline \multirow[t]{2}{*}{ Factors Associated with Prosocial Behaviors } & \multicolumn{3}{|c|}{ Model } \\
\hline & PR & $95 \% \mathrm{CI}$ & \\
\hline \multicolumn{4}{|l|}{ Age } \\
\hline Below 30 years old & REF & & \\
\hline $30-40$ years old & 1.03 & $0.79-1.33$ & \\
\hline Above 40 years old & 1.34 & $1.05-1.70$ & * \\
\hline \multicolumn{4}{|l|}{ Gender } \\
\hline Female & REF & & \\
\hline Male & 0.94 & $0.83-1.07$ & \\
\hline \multicolumn{4}{|l|}{ Occupation } \\
\hline Students & REF & & \\
\hline Teachers/Lecturers & 1.20 & $0.88-1.63$ & \\
\hline Admin & 1.07 & $0.77-1.48$ & \\
\hline Businessmen, freelances & 1.30 & $0.94-1.81$ & \\
\hline Medical staff & 1.25 & $0.78-2.02$ & \\
\hline \multicolumn{4}{|l|}{ Institutional trust } \\
\hline Low trust & REF & & \\
\hline High trust & 1.70 & $1.07-2.71$ & * \\
\hline$* \mathrm{p}<0.05, * * \mathrm{p}<0.01, * * * \mathrm{p}<0.001$ & & & \\
\hline
\end{tabular}

\subsection{Factors Associated with Prosocial Behaviors}

Table 3 presented factors associated with prosocial behaviors among the Vietnamese population during the COVID-19 pandemic. In the multivariate regression model, age and institutional trust were associated factors that affected the prevalence of prosocial behaviors. Respondents above 40 years old were 1.34 times more likely to conduct prosocial behaviors than respondents below 30 years old $(\mathrm{PR}=1.34$, $95 \%$ CI: $1.05-1.70)$. Institutional trust significantly increased the frequency of prosocial behaviors (PR $=1.70,95 \% \mathrm{CI}: 1.07$ $-2.71)$.

\section{DISCUSSION}

The present article aims to estimate the prevalence of prosocial behaviors during the COVID-19 pandemic and examine its associated predictors. This study is among the first research to examine the impact of institutional trust on prosocial behaviors during a crisis situation (COVID-19 pandemic) in a collectivistic setting (Vietnamese culture). Besides theoretical and scientific implications, these results provide useful information to governments to devise policies and social education programs to encourage prosocial behaviors during the pandemic.

\subsection{Prevalence of Prosocial Behaviors During the COVID-19 Pandemic}

This study found a very high rate (75.3\%) of people conducting frequent prosocial behaviors during the COVID-19 pandemic in Vietnam. Crises such as natural disasters and disease outbreaks make salient the need for immediate assistance for people in the affected areas. The greater the perceived needs, the more support provided. In Hurricane Hugo, victims of the hurricane received significantly more help than non-victims; victims suffering from high loss received more support than those with the low loss [37]. In the Wenchuan Earthquake, nearly half of local authorities in the affected area agreed that allocation of relief materials and 
funds had been given first and foremost to households suffering greater losses [38]. However, it should be noted that prosocial behaviors during crises follow the rule of relative need: the amount of support depends on the helper's judgment of loss, not the actual amount of loss. For example, people can lend money not only to those suffering from the crisis but also to people living near the area of suffering, believing that these people are also affected by the crisis. During the Ebola outbreak, people lent more money through an online platform for borrowers from countries near the affected areas (i.e., West African countries) than those living far from the affected areas, such as East African or Asian countries [39]. As a result, the more information available about the consequences of crises, the more likely prosocial behaviors would be conducted.

In the case of Vietnam, since the beginning of the COVID-19 outbreak, information coverage of the pandemic has focused on messages of prevention, control, and individual responsibilities in overcoming the pandemic. Effects of the pandemic have been portrayed in a multisectoral aspect: any citizen can be exposed to health risks, economic loss, fake new challenges, restricted travelling, etc [40]. Moreover, the pandemic has been portrayed to affect all social groups, from the old to the young, from people at the frontline of the battle (medical staff, police, and military personnel) to people from all walks of life. Such media coverage strategy increases public awareness of the effect of the COVID-19 pandemic and helps promote immediate prosocial behaviors during and after the pandemic.

However, the prevalence of prosocial behaviors in this study is much higher than the reported rate of helping behaviors in some previous studies. For example, this rate is higher than the average helping behaviors in everyday situations. In Levine, Norenzayan [41], of 23 countries participating in field experiments on helping behavior, only 9 countries had an overall rate of helping behaviors above $75 \%$. When compared to report of other crises, the prevalence of prosocial behaviors in the current study was also higher. For example, in Hurricane Hugo, of 16 prosocial behaviors surveyed, only 3 behaviors had a mean score higher than 3 on a scale from 1 (never) to 4 (many times) [37].

We believe that the explanation for this high rate of frequent prosocial behaviors of Vietnamese during the COVID-19 pandemic is in the strong sense of community raised during the pandemic. In any crisis, not specifically the COVID-19 pandemic, there is usually a heightened sense of connectedness among people affected by the crisis [42, 43]. The shared sufferings and distress bring victims together, thus promoting prosocial behaviors. However, what makes the case of Vietnam considerably different from other crises is this sense of community is not only the natural side effect of the occurrence of the pandemic but is also the result of the government's framing of the pandemic. To begin with, unlike natural disasters like Hurricane Katrina and Hurricane Hugo, which affected specific geographic areas, the COVID-19 pandemic is portrayed in the media as affecting anyone. Interestingly, disaster victims tend to provide more support to other victims; those who lose more are those who provide the most support [37]. As a result, when the Vietnamese government stresses that anyone can be a victim of the COVID-19 pandemic, everyone feels the need to help other sufferers. Fellow citizens are no longer strangers but become the in-group: the group of people sharing the same risks and difficulties. Secondly, the message that the Vietnamese government holds on to during the pandemic control is "fighting the pandemic like fighting an enemy" [40]. This message touches the heroic history of national defense, thereby activating a sense of unity, connectedness. It should be noted that this message does not create fear but rather raises confidence in overcoming difficulties, similar to how the Vietnamese have won over many huge colonists. These two features explain the strong, widespread sense of community among Vietnamese during the COVID-19 pandemic, which in turn motivates a high rate of frequent prosocial behaviors.

\subsection{Institutional Trust and Prosocial Behaviors in a Collectivistic Culture}

This study tests the hypothesis that institutional trust is associated with prosocial behavior in a collectivistic culture. The findings of this study support the proposed hypothesis. People with high institutional trust, in particular trust in the government's response to the COVID-19 pandemic, conducted more prosocial behaviors. This study provides additional support for the growing evidence on the positive link between institutional trust and prosocial behaviors in collectivistic cultures, as found in Japan [44] and Palestine [17].

Evidence of both mechanisms can be found in the case of Vietnam. The Vietnamese government's response to COVID-19 has elicited a sense of social equality and strict control of cheating behaviors. Economic support was provided as early as 15 days after the first recorded case of COVID-19 in Vietnam. Tax exemption for medical supplies and free quarantine fees and testing costs were issued in February 2020, followed by an economic stimulation package of USD 10 million and a social welfare package of USD 2.6 million in April 2020 [45]. For the first 12 months of the pandemic, the government covered the allowance and medical fees of people in medical isolation centers, Vietnamese and foreigners alike, [46]. Only since $8^{\text {th }}$ February 2021, foreigners entering Vietnam have to pay allowance and medical fees during quarantine [47]. These regulations assure the public that the government cares for both citizens' and non-citizens' benefits.

To control cheating behaviors, new policies on sanctions against people disrupting pandemic control were issued even before the first case of COVID-19 in Vietnam [45]. Fines of VND 5-15 million (USD 215-650) have been imposed on people posting or sharing fake news about the pandemic [46, 48]. Information about these fines is publicized on national newspapers and television channels, making all citizens aware of the punishment on misinformation. Behaviors to take advantage of donation programs to support the poor and disadvantaged are morally condemned while not legally punished. For example, big news channels such as Lao Dong newspaper, VTC, Thanh Nien newspaper, etc., have reported cases of chaos during food donation distribution, or rich people are queueing to get donated stuff as examples of violation of social norms during a difficult time $[49,50]$. Both legal and 
social means to control cheating behaviors during the COVID-19 pandemic have strengthened public trust in the government's responses to COVID-19 and ensured prosocial behaviors to effectively reach people in need.

While this study cannot answer which of the two mechanisms was responsible for the effect of institutional trust in a collectivistic culture, it showed that institutional trust predicted prosocial behaviors in a collectivistic culture. It should be noted that institutional trust examined in this study is not general trust but rather situation-specific trust: trust in government's response to COVID-19. This finding has important implications for designing social education programs in crisis contexts, as discussed later.

\subsection{Age and Prosocial Behaviors}

Our findings showed that older adults (people aged 40 and above) are significantly more likely to help others than younger adults. This finding is in line with previous studies. Sze, Gyurak [51] found that age increases emotional empathy and prosocial behaviors. The effect of age on empathy and prosocial behaviors was so robust that it was observed across measures: self-reports and physiological response. The effect was also observed in children, with older children being more likely to engage in prosocial behaviors [52].

Because the age impact is linked to social capital, we believed that the age effect would remain while the gender effect would not. Older adults have higher social capital, which is essential for prosocial behaviors. They are more likely to be economically independent, have higher income, and have more social connections that make short-term helping and donation easier. Given that all participants in this study were at the age of young adulthood and above, the difference in value orientation across developmental stages is less significant and thus contributes little to differences in prosocial behaviors in crises, but rather the difference in social capital across age would be of more importance.

\subsection{Strengths and Limitations}

To our knowledge, this is the first study in Vietnam to investigate associated factors for prosocial behaviors among the Vietnamese population during the COVID-19 pandemic, such as institutional trust and age.

The main limitation of this study is in the sampling process. The advantage of this sampling method will be stronger if the initial respondents come from a demographically diverse group [53]. However, all initial respondents in this study work in organizations funded by the public sector (i.e., university lecturer, admin, healthcare workers). As a result, nearly half of the recruited participants work in the public sector. People working in the public sector have the edge over those working in the private sector during the COVID-19 pandemic: the former has low yet stable income during this difficult time, while the pandemic can severely hit the latter due to job loss or economic recession. This might slightly inflate the reported prevalence of prosocial behaviors. Future studies should take into account the financial capacity of the helpers when studying prosocial behaviors.

\section{CONCLUSION AND IMPLICATIONS FOR SOCIAL EDUCATION PROGRAMS}

Our study found that the prevalence of prosocial behaviors among the Vietnamese population during the COVID-19 pandemic was quite high. This study provided support to the impact of age and institutional trust on prosocial behaviors during the COVID-19 pandemic in a collectivistic setting (Vietnamese culture).

The findings have important implications for social education programs. Previous studies have pointed out various predictors of prosocial behavior, from contextual factors such as salience of social norms, the emotion of the helper, etc., to dispositional factors such as empathy, responsibility, etc [1]. However, if a society wants to encourage its citizens' prosociality in a pandemic, it is impossible to address these factors. For example, a TV social education program can put its target audience into a good mood and increase their donation behavior immediately after watching the program, but it cannot prolong this mood so that the viewers can sustain their prosocial act. It is essential to consider the impacts of factors that mass education interventions can easily address. Trust in the government's response to a certain issue can be increased by creating the image of a transparent government [54], as well as fast and accurate communication [55].

Given the role of institutional trust in prosocial behaviors in collectivistic cultures, social education programs should focus more on creating institutional trust, especially trust in the government's response to the crises. During both waves of the pandemic, the Vietnamese government has focused on presenting the image of a transparent government that informs its citizens, supports its people, and works for the benefit of the people. This strategy has gained institutional trust among the Vietnamese people. Other collectivistic countries can run similar campaigns to raise institutional trust, thereby promoting prosocial behaviors.

\section{ETHICS APPROVAL AND CONSENT TO PARTICIPATE}

Not applicable.

\section{HUMAN AND ANIMAL RIGHTS}

No animals/humans were used for studies that are the basis of this research.

\section{CONSENT FOR PUBLICATION}

Not applicable.

\section{STANDARDS OF REPORTING}

STROBE guidelines have been followed in this study.

\section{AVAILABILITY OF DATA AND MATERIALS}

The data that support the findings of this study are available from the corresponding author [T.V.T] upon reasonable request. 


\section{FUNDING}

None.

\section{CONFLICT OF INTEREST}

The authors declare no conflict of interest, financial or otherwise.

\section{ACKNOWLEDEGMENTS}

Declared none.

\section{REFERENCES}

[1] Eisenberg N, Sadovsky A. Prosocial behavior, development of, in encyclopedia of applied psychology. New York: Elsevier 2004; pp. 137-41.

[http://dx.doi.org/10.1016/B0-12-657410-3/00076-3]

[2] Silva JL, Marks LD, Cherry KE. The psychology behind helping and prosocial behaviors: An examination from intention to action.Lifespan perspectives on natural disasters. Springer 2009; pp. 219-40.

[http://dx.doi.org/10.1007/978-1-4419-0393-8_11]

[3] Godbole T. Coronavirus: Indians turn to social media in search of oxygen, beds In: DW. 2021

[4] News V. Text message support raises \$5,4m for COVID-19 prevention, control In: Vietnam News. 2020

[5] Duong Y. Rice ATM' feeds Vietnam's poor amid virus lockdown In: Reuters. 2020.

[6] Tran J. First 'Zero-VND Happy Supermarket' launched in Ho Chi Minh city In: Vietnam Times. 2020.

[7] Burnstein E, Crandall C, Kitayama S. SSome neo-Darwinian decision rules for altruism: Weighing cues for inclusive fitness as a function of the biological importance of the decision. J Soc Psychol 1994; 67(5): 773 .

[8] Rotenberg KJ. The relation between interpersonal trust and adjustment: Is trust always good?Trust in Contemporary Society. Brill 2019; pp. 161-74.

[9] Padilla-Walker LM, Carlo G, Memmott-Elison MKJJoRoA. Longitudinal change in adolescents' prosocial behavior toward strangers, friends, and family 2018; 28(3): 698-710. [http://dx.doi.org/10.1111/jora.12362]

[10] Echols S, Correll J. It's more than skin deep: Empathy and helping behavior across social groups In: Empathy: From Bench to Bedside, J Decety. 2011.

[http://dx.doi.org/10.7551/mitpress/9780262016612.003.0004]

[11] Knafo A, Schwartz SH, Levine RV. Helping strangers is lower in embedded cultures. J Cross Cult Psychol 2009; 40(5): 875-9.

[http://dx.doi.org/10.1177/0022022109339211]

[12] Dávila de León MC, Finkelstein MA. Individualism/collectivism and organizational citizenship behavior. Psicothema 2011; 23(3): 401-6. [PMID: 21774892]

[13] Puyod JV, Charoensukmongkol PJA-PSSR. Interacting effect of social media crisis communication and organizational citizenship behavior on employees' resistance to change during the COVID-19 Crisis: Evidence from university employees in the philippines. Asia-Pacific Soc Sci Rev 2021; 21(3)

[14] Irwin K. Prosocial behavior across cultures: The effects of institutional versus generalized trust.Altruism and prosocial behavior in groups. Emerald Group Publishing Limited 2009.

[http://dx.doi.org/10.1108/S0882-6145(2009)0000026010]

[15] Yamagishi T, Yamagishi M. Trust and commitment in the United States and Japan. Motiv Emot 1994; 18(2): 129-66. [http://dx.doi.org/10.1007/BF02249397]

[16] Yamagishi T. The provision of a sanctioning system in the united states and Japan. Soc Psychol Q 1988; 51(3): 265-71. [http://dx.doi.org/10.2307/2786924]

[17] Andriani L, Sabatini F. Trust and prosocial behaviour in a process of state capacity building: The case of the Palestinian territories. J Inst Econ 2015; 11(4): 823-46. [http://dx.doi.org/10.1017/S1744137414000575]

[18] Ervasti H, Kouvo A, Venetoklis T. Social and institutional trust in times of crisis: Greece, 2002-2011. Soc Indic Res 2019; 141(3): 1207-31.

[http://dx.doi.org/10.1007/s11205-018-1862-y]

[19] Roth F. The effect of the financial crisis on systemic trust. Inter Econ
2009; 44(4): 203-8.

[http://dx.doi.org/10.1007/s10272-009-0296-9]

[20] Cheung CK, Tse JW. Institutional trust as a determinant of anxiety during the SARS crisis in Hong Kong. Soc Work Public Health 2008; 23(5): 41-54.

[http://dx.doi.org/10.1080/19371910802053224] [PMID: 19301537]

[21] Györffy DJSB. Trust and crisis management in the European Union 2018.

[http://dx.doi.org/10.1007/978-3-319-69212-8]

[22] Bavel JJV, Baicker K, Boggio PS. Using social and behavioural science to support COVID-19 pandemic response. Nat Hum Behav 2020; 4(5): 460-71.

2020; 4(5): 460-71.
[http://dx.doi.org/10.1038/s41562-020-0884-z] [PMID: 32355299]

[23] Hamilton W. The evolution of altruistic behavior. Am Nat 1963. [http://dx.doi.org/10.1086/497114]

[24] Batson CD, Coke JS, et al. Empathy: A source of altruistic motivation for helping. Altruism and helping behavior: Social, personality, and developmental perspectives 1981; 167-87.

[25] Cialdini RB, Baumann DJ, Kenrick DT. Insights from sadness: A three-step model of the development of altruism as hedonism. Dev Rev 1981; 1(3): 207-23.

[http://dx.doi.org/10.1016/0273-2297(81)90018-6]

[26] Dovidio JF, Piliavin JA, Gaertner SL, Schroeder DA, Clark RD III. The arousal: Cost-reward model and the process of intervention: A review of the evidence.Prosocial behavior. Washington: Sage Publications Inc. 1991; pp. 86-118.

[27] Dovidio JF, Piliavin JA, Schroeder DA, Penner LA. The social psychology of prosocial behavior. Psychology Press 2017.

[http://dx.doi.org/10.4324/9781315085241]

[28] Parks CD, Hulbert LG. High and low trusters' responses to fear in a payoff matrix. J Conf Res 1995; 39(4): 718-30.

[http://dx.doi.org/10.1177/0022002795039004006]

[29] Kumlin S, Rothstein B. Making and breaking social capital: The impact of welfare-state institutions. Compar Polit Stud 2005; 38(4): 339-65.

[http://dx.doi.org/10.1177/0010414004273203]

[30] Evers A, Gesthuizen M. The impact of generalized and institutional trust on donating to activist, leisure, and interest organizations: individual and contextual effects. Int J Nonprof Volunt Sect Mark 2011; 16(4): 381-92.

[http://dx.doi.org/10.1002/nvsm.434]

[31] Alvis L, Shook N, Oosterhoff B. Adolescents' prosocial experiences during the covid-19 pandemic: Associations with mental health and community attachments. PsyArXiv [Preprints] 2020.

[32] Han Q, Zheng B, Cristea M, et al. Trust in government and its associations with health behaviour and prosocial behaviour during the COVID-19 pandemic. PsyArXiv Preprints 2020.

[http://dx.doi.org/10.31234/osf.io/p5gns]

[33] Sibley CG, Greaves LM, Satherley N, et al. Effects of the COVID-19 pandemic and nationwide lockdown on trust, attitudes toward government, and well-being. Am Psychol 2020; 75(5): 618-30. [http://dx.doi.org/10.1037/amp0000662] [PMID: 32496074]

[34] Zou G. A modified poisson regression approach to prospective studies with binary data. Am J Epidemiol 2004; 159(7): 702-6. [http://dx.doi.org/10.1093/aje/kwh090] [PMID: 15033648]

[35] Barros AJ, Hirakata VN. Alternatives for logistic regression in crosssectional studies: An empirical comparison of models that directly estimate the prevalence ratio. BMC Med Res Methodol 2003; 3(1): 21. [http://dx.doi.org/10.1186/1471-2288-3-21] [PMID: 14567763]

[36] Chen W, Qian L, Shi J, Franklin M. Comparing performance between log-binomial and robust Poisson regression models for estimating risk ratios under model misspecification. BMC Med Res Methodol 2018; 18(1): 63 .

[http://dx.doi.org/10.1186/s12874-018-0519-5] [PMID: 29929477]

[37] Kaniasty K, Norris FH. In search of altruistic community: Patterns of social support mobilization following Hurricane Hugo. Am J Community Psychol 1995; 23(4): 447-77. [http://dx.doi.org/10.1007/BF02506964] [PMID: 8546107]

[38] Hu X, Salazar MA, Zhang Q, Lu Q, Zhang X. Social protection during disasters: evidence from the Wenchuan earthquake. IDS Bull 2010; 41(4): 107-15.

[http://dx.doi.org/10.1111/j.1759-5436.2010.00157.x]

[39] Ding Y, Xu H, Yang L, Tan BC. Online Prosocial microlending decision making: A natural experiment of Ebola outbreak https://www.findevgateway.org/sites/default/files/publications/2020/E bola.dxyt_icis2016\%20(1).pdf

[40] Ha BTT, Ngoc Quang L, Mirzoev T, Tai NT, Thai PQ, Dinh PC. 
Combating the COVID-19 epidemic: Experiences from vietnam. Int $\mathrm{J}$ Environ Res Public Health 2020; 17(9): 3125.

[http://dx.doi.org/10.3390/ijerph17093125] [PMID: 32365851]

[41] Levine RV, Norenzayan A, Philbrick K. Cross-cultural differences in helping strangers. J Cross Cult Psychol 2001; 32(5): 543-60. [http://dx.doi.org/10.1177/0022022101032005002]

[42] Jacob B, Mawson AR, Payton M, Guignard JC. Disaster mythology and fact: Hurricane Katrina and social attachment. Public Health Rep 2008; 123(5): 555-66.

[http://dx.doi.org/10.1177/003335490812300505] [PMID: 18828410]

[43] Vezzali L, Drury J, Versari A, Cadamuro A. Sharing distress increases helping and contact intentions via social identification and inclusion of the other in the self: Children's prosocial behaviour after an earthquake. Group Process Intergroup Relat 2016; 19(3): 314-27. [http://dx.doi.org/10.1177/1368430215590492]

[44] Taniguchi H, Marshall GA. The effects of social trust and institutional trust on formal volunteering and charitable giving in Japan. Voluntas 2014; 25(1): 150-75.

[http://dx.doi.org/10.1007/s11266-012-9328-3]

[45] Tran TPT, Le TH, Nguyen TNP, Hoang VM. Rapid response to the COVID-19 pandemic: Vietnam government's experience and preliminary success. J Glob Health 2020; 10(2): 020502. [http://dx.doi.org/10.7189/jogh.10.020502] [PMID: 33110585]

[46] Nguyen TV, Tran QD, Phan LT, et al. In the interest of public safety: Rapid response to the COVID-19 epidemic in Vietnam. BMJ Glob Health 2021; 6(1): e004100.

[http://dx.doi.org/10.1136/bmjgh-2020-004100] [PMID: 33495284]
[47] Government T. Resolution No. 16/NQ-CP on fees for quarantine, diagnosis and treatment of COVID-19. In: 16/NQ-CP. 2021

[48] Nguyen TH, Vu DC. Impacts of the COVID-19 pandemic upon mental health: Perspectives from Vietnam. Psychol Trauma: Theory Res Pract Policy 2020; 12(5): 480.

[49] Anh T. Nonpoor queueing for donated packages: Low self-esteem In: Thanh Nien. 2020.

[50] News V. Terrible manner: The wealthy "robs" donation for the poor admist the pandemic In: VTC News. 2020.

[51] Sze JA, Gyurak A, Goodkind MS, Levenson RW. Greater emotional empathy and prosocial behavior in late life. Emotion 2012; 12(5): 1129-40.

[http://dx.doi.org/10.1037/a0025011] [PMID: 21859198]

[52] Fabes RA, Eisenberg N. Meta-analyses of age and sex differences in children's and adolescents' prosocial behavior. Handbook of Child Psychology 1998; 3: 1-29.

[53] Wejnert C, Heckathorn DD. Web-based network sampling: efficiency and efficacy of respondent-driven sampling for online research. Sociol Method Res 2008; 37(1): 105-34.

[54] Cook FL, Jacobs LR, Kim D. Trusting what you know: Information, knowledge, and confidence in social security. J Polit 2010; 72(2): 397-412.

[http://dx.doi.org/10.1017/S0022381610000034]

[55] La V-P, Pham TH, Ho MT, et al. Policy response, social media and science journalism for the sustainability of the public health system amid the COVID-19 outbreak: the Vietnam lessons. Sustainability 2020; 12(7): 2931.

[http://dx.doi.org/10.3390/su12072931]

\section{(C) 2021 Thu et al.}

This is an open access article distributed under the terms of the Creative Commons Attribution 4.0 International Public License (CC-BY 4.0), a copy of which is available at: https://creativecommons.org/licenses/by/4.0/legalcode. This license permits unrestricted use, distribution, and reproduction in any medium, provided the original author and source are credited. 